\title{
Why our Family? Parental Responses to Cyberbullying
}

\author{
Tegan E. Lynch, Vanessa A. Green, Chris Bowden and Susan Harcourt \\ Victoria University of Wellington
}

\begin{abstract}
Cyberbullying is a significant issue among young people both in New Zealand and internationally. To develop effective and unified prevention and intervention strategies, it is important to understand the perspectives of all parties. However, there is currently limited research on parents' perspectives of cyberbullying. This applied research project has analysed parents' responses to their child being cyberbullied. An anonymous, online questionnaire yielded responses to seven questions from ten participants. These qualitative responses were analysed thematically to produce overarching themes that reflect the experiences of parents whose children have been cyberbullied. The ten participants' responses revealed that parents have a range of emotional reactions and take a variety of actions in response to their child being cyberbullied. They also feel that multiple parties are responsible for intervening in cyberbullying. Limitations, future directions, and implications for successful homeschool partnerships are discussed.
\end{abstract}

Keywords: Cyberbullying, parents experiences, qualitative research

\section{Research Paper}

\section{INTRODUCTION}

Bullying is a widespread issue which has been linked to a variety of adverse outcomes for children and young people, such as depression and suicide ideation (Turner, Exum, Brame \& Holt, 2013). One recent cross-national study of 1,378 adolescents reported that 32.7 percent of male and 36.4 percent of female participants had been cyberbullied (Hinduja \& Patchin, 2007). Moreover, bullying may have negative effects on both the victim and the bully. That is, bullies have been shown to be at greater risk of being engaged in other adverse behaviours and activities, such as substance abuse and delinquency (Ybarra \& Mitchell, 2004).
Cyberbullying is commonly defined as "an aggressive, intentional act carried out by a group or individual, using electronic forms of contact, repeatedly and over time against a victim who cannot easily defend him or herself" (Smith \& Slonje, 2010, p. 249). This can include cellphone bullying, picture/video clip sharing, intimidation, harassment, embarrassment, or exclusion through the use of technology. Beale and Hall (2007) argue that the development of recent technology has influenced cyberbullying as perpetrators are able to 'hide behind the screen'. As such, accountability for bullying, identification of bullies, and risk of punishment are all diminished.

For cyberbullying in particular, the reach of bullies' actions is unrestricted; it can occur across contexts, in any location and at any time. That is, it can occur beyond the school and within the home (Beale \& Hall, 2007). As such, teachers report confusion over the responsibility of dealing with cyberbullying related to the location in which cyberbullying occurs (Green, Harcourt, Mattioni \& Prior, 2013). Teachers report that, since the bullying often occurs both in school and at home, the responsibility of dealing with cyberbullying should be shared across these environments. It is currently unclear whom parents see as responsible for dealing with cyberbullying: this could differ from the view of teachers. Consequently, this confusion may be a barrier to effective prevention and intervention of cyberbullying situations.

As the location of cyberbullying can vary, and many parties may be involved, it is important to explore wider perspectives and responses to cyberbullying situations. Effective prevention and intervention strategies require a multi-systemic approach that involves families, schools, and the wider community working together (Olweus, 1993). However, before this collaborative approach can happen, all parties need to understand the views and perspectives of each other. Dehue, Bolman and Völlink (2008) identified that most research on cyberbullying that does include the adult perspective has focused on the teacher's views. As such, there is currently limited 
research on parents' perspectives of cyberbullying and they have only recently been researched in relation to traditional bullying (Sawyer, Mishna, Pepler, \& Wiener, 2011).

Sawyer et al. (2011) conducted in-depth interviews with 20 parents whose children had disclosed experiencing traditional bullying. This qualitative research found significant variation in participants' definition of bullying, how they identified bullying behaviours, and what parents suggested to their children to try to overcome the bullying. During the study, some of the parents had been previously unaware that their child had been bullied. Their reactions included feeling "very surprised" that their child was bullied and some parents described "not being surprised" because they viewed bullying as an unavoidable part of growing up. Parents also described their children's reaction to being bullied. These included school avoidance, psychological effects, and emotional responses. One limitation of this study was that some parents found out about the bullying while they participated. Therefore, this study was unable to provide information about what they did next, or where they turned for support or intervention. Furthermore, no incidences of cyberbullying were discussed. Sawyer et al. (2011) further explained the importance of the parent's perspectives of bullying as their views can greatly affect their response to bullying situations and the subsequent effectiveness of their response.

Another recent qualitative study exploring parents' experiences, in relation to traditional bullying, only included parents who were aware that their child had been bullied. In this study, Harcourt (2013) found that parents experienced a range of emotional responses to their children's bullying - both negative (e.g. distress) and positive (e.g. increased resiliency). Harcourt discussed parents' views on the responses, both positive and negative, and the responsibility of schools. This study did not contain the perspectives of parents whose children have experienced cyberbullying. The current study addresses this by specifically focusing on the parents of children who have experienced cyberbullying. Moreover, Harcourt also recognised the need for future research to focus on understanding parents' use of strategies and the sources of information and advice that parents utilise in responding to bullying situations. The current study addresses this and identifies the action parents take when supporting their child through cyberbullying situations.

Several studies on cyberbullying that include the parents' perspective have used quantitative research methods. One such study by Dehue et al. (2008), using a questionnaire, found that parents reported lower levels of children engaging in cyberbullying (4.8 percent) than children reported (17.3 percent). Parents also reported lower levels of children being cyberbullied (11.8 percent) than children reported (22.9 percent). That is, Dehue et al. (2008) found that parents underestimated the extent to which their children were being cyberbullied and/or were cyberbullying others. There is a distinct lack of similar qualitative research: such that, a recent systematic review looking at qualitative research from parents' perspectives in all forms of bullying found 13 studies, of which only two specified cyberbullying (Harcourt, Jasperse \& Green, 2014). The first of these studies, Cassidy, Brown and Jackson (2012), used a qualitative questionnaire to examine parents' knowledge of social networking, their experiences with and level of concern of cyberbullying, and ideas for cyberbullying prevention. The second study identified by Harcourt et al. investigated perceptions of cyberbullying in three Hawai'i middle schools using a questionnaire and semi-structured interviews with three parents (Mark, 2009). However, it was not clear if the children of these parents had personally experienced cyberbullying.

One overarching conclusion from these two studies is that parents appeared to be less concerned about cyberbullying than children (Cassidy et al., 2012; Mark, 2009). However, this could be because they were not as aware of cyberbullying, and thought of it as less serious than children and young people did (Cassidy et al., 2012; Mark, 2009). This is further supported by the evidence of parental underestimation found by Dehue et al. (2008). Furthermore, while parents viewed the school as having a role in the prevention of cyberbullying (Cassidy et al., 2012), there was also confusion over the differing responsibilities of parents and schools concerning the prevention of, and intervention in, cyberbullying situations (Mark, 2009). Overall, these conclusions illustrate the need for further research with parents whose children have been cyberbullied, so as to describe their personal experiences and identify their views on the responsibility for intervention.

This review has identified an opportunity to contribute to the existing literature by addressing the current research gaps. These research gaps include a lack of qualitative research from the perspective of parents whose children have been cyberbullied, the action these parents take, where they turn for support, and who they see as responsible for intervening. The current study sought to answer three main research questions. The three research questions were: 
1. How do parents personally and emotionally respond to their child being cyberbullied?

2. What actions do parents take and what support do they utilise in response to their child being cyberbullied?

3. Who do parents see as responsible for intervening in cyberbullying situations?

\section{METHOD}

\section{Ethical clearance and informed consent}

Ethical clearance was gained for this research from the Human Ethics Committee at Victoria University of Wellington. An informed consent form was provided at the beginning of the questionnaire. Participants were required to indicate that they had read an information sheet and the consent form and were voluntarily participating before they could proceed to the questionnaire.

\section{Questionnaire development}

The current study utilised a qualitative research method in the form of an online questionnaire with open-ended questions whereby parents described their experiences, feelings and responses to the cyberbullying of their children. Participating parents and caregivers were invited to respond to the anonymous questionnaire, hosted on the Qualtrics survey website. The questionnaire was adapted from that of Harcourt (2013). The questionnaire consisted primarily of open-ended, qualitative questions asking participants to describe their response to their child being cyberbullied. The questionnaire also included several questions regarding specific details of their child's cyberbullying experience, and collected basic demographic information. The qualitative questions in the questionnaire were:

1. Please describe your thoughts and feelings when you first found out about the cyberbullying.

2. Please describe, in as much detail as you can, what effects the cyberbullying had on you personally, your child, and your other family members (i.e. your emotions as you went through the process of responding to the cyberbullying).

3. Please describe, in as much detail as you can, how you responded when you found out your child had been/was being cyberbullied (i.e. any action you took).

4. What were the effects of these actions on your child and the situation?

5. Did you receive any form of support or advice while dealing with the cyberbullying?
- [If 'yes' was selected] please describe this support or advice.

- [If 'no' was selected] what type of support or advice would you have liked?

6. Please explain who you think is responsible for intervening in cyberbullying situations and supporting those experiencing cyberbullying and their families.

7. Do you have anything else you would like to say about your experience of supporting your child during his/her experience of cyberbullying? Please share any further comments you may have, remembering that your responses will remain anonymous.

\section{Participant recruitment}

This project aimed to recruit parents or primary caregivers of a child from any age group who was currently experiencing, or had previously experienced, cyberbullying. Given that a wide range of children and young people may experience cyberbullying, the demographic characteristics of participating parents (such as age or ethnicity) were expected to vary widely; therefore, no restrictions were placed on these or other demographic characteristics during participant recruitment. As participation was anonymous, participants completing the questionnaire were asked to ensure that no identifying information be included in their responses.

Firstly, a webpage was created for this project at cyberbullyingsurvey.com. Similar to the website used in Harcourt (2013), this website provided potential participants with general information about the project, described what participating in the study would involve, and introduced the student researcher, project supervisors, and provided contact details. It displayed links to websites where parents could find resources and support for dealing with cyberbullying. Finally, it provided a link to the questionnaire on the Qualtrics website. The advantage of this webpage was that potential participants may have found it easier to go to the webpage address than typing the complex details of the Qualtrics website link.

Secondly, recruitment notices advertising the project and the webpage address were distributed in one New Zealand city. Paper copies of the notices were placed in public locations where parents may have seen them. In addition, national parenting support groups and organisations (e.g. Skylight Trust) were contacted with a request to post the notices on their websites, social media pages and newsletters. Lastly, following on from media interest in prior bullying research at Victoria University of Wellington, two local newspapers were contacted about the research 
and two subsequent articles were released. These articles could also be accessed online and therefore nationally. Harcourt (2013) recognised the success of recruitment through social networking: that is, 81 percent of participants stated that they had heard about the study through email or Facebook. Additionally, this recruitment method has been detailed by O'Connor, Jackson, Goldsmith and Skirton (2014) who evaluated the social networking site Twitter as a means of getting participants for online health research. They established that Twitter was an effective means of recruitment which enabled researchers to engage with difficult-toreach populations while also providing anonymity, accessibility and convenience. Therefore, the researcher of the current study advertised the project throughout her social media networks (i.e. Twitter and Facebook), encouraging participants to forward the link on to interested parents.

\section{Data analysis}

The analysis developed themes that were linked to, and driven by, the data with no predetermined coding scheme that data were required to fit (Braun \& Clark, 2006). This study performed a thematic analysis using the steps outlined in Braun and Clark (2006). These six steps were:

1. Familiarising yourself with your data. This included reading and re-reading the data, noting down any initial ideas.

2. Generating initial codes. This involved coding features of the entire data set and ordering data into relevant codes.

3. Searching for themes. After ordering data into codes, the codes were collated into potential themes.

4. Reviewing themes. This involved checking if the themes worked in relation to individual codes and the entire data set.

5. Defining and naming themes. This involved ongoing analysis to refine the themes, overall analysis, and developing clear names and definitions for themes.

6. Producing the report. Lastly, the researcher selected extracts from the data that related to the research questions and existing literature, and used these to produce a scholarly report of the analysis.

Data was refined through re-reading to develop a comprehensive coding scheme; meanwhile, any errors were identified and corrected before being incorporated into the analysis. Dependability of data was checked through a co-author to ensure that codes, themes and overall analysis were consistent and valid. This process resulted in 100 percent agreement.

\section{RESULTS}

\section{Participants}

During the twelve-week data collection, a total of 11 surveys were completed. One response was excluded as it did not meet the definition of cyberbullying. This left a total of ten responses to be analysed in this study. Of the nine participants that indicated their age, the mean age of respondents was 44.8 years. Nine out of 10 participants were women; all nine were the mother of the child they discussed. The remaining participant was a male and the father of the child they discussed. Four participants indicated they heard about the research through Facebook, four through their child's school, one through a newspaper article about the research, and one via word-ofmouth. All participants indicated that they lived in New Zealand at the time of the cyberbullying.

Participants' children ranged in age from 11-17 years. The mean age of participants' children when the cyberbullying began was 13.6 years, with a standard deviation of 1.9 years. Six participants specified that the child they discussed was female, and four were male. Seven out of 10 participants indicated the bullying had been going on for zero to one month before they found out. Nine participants identified that their child knew the cyberbully; one participant's child was unsure of who the cyberbully was.

\section{Main findings}

Parents responded to incidents of cyberbullying in three main ways: their initial reactions focused on addressing the hurt their child had experienced, they then took action and finally, they reflected on, and tried to engage with, those who they thought should take responsibility. The findings from this study are ordered into three major themes that reflect these responses. The themes and categories will then be discussed in relation to theory and research on cyberbullying and linked back to the research questions.

\section{THEME 1: UNABLE TO UNDO THE DAMAGE}

Parents described different personal and emotional responses to their child being cyberbullied. Most initial reactions involved a negative emotional response to the perceived trauma and damage their child had experienced. These initial reactions also involved feelings of empathy towards their child and reflection on the meaning of the event in relation to parenting identity, skills and needs. Many parents described cyberbullying and the accompanying responses as contributing to family and/or marital stress. The resounding message was that parents felt 
"hopelessness in being able to undo the damage done" to them, their child, and their family.

\section{a) Emotional reactions toward the event/s}

Parents described experiencing powerful emotional responses to their child being cyberbullied. Five parents described feeling angry about what happened. One parent described feeling "upset, angry, [and] determined to bring the bully to justice". This reaction and desire to confront the bullies was echoed in the responses of other parents: "My husband was angry and wanted to confront the bullies". Three parents also reported experiencing feelings of hopelessness that were related to their inability to prevent the event and the subsequent suffering. One parent said: "There weren't many thoughts. Just a feeling of hopelessness that a machine could enable such hurt and destruction". However, not all parents reported feeling angry and hopeless. One parent described feeling proud that her child had felt she could approach her and had talked to her about the cyberbullying: "Fortunately my daughter showed me the text messages when she found out and I was very proud of her". This is an example of a parent wanting to support their child through cyberbullying and wanting to be approached when it happened.

\section{b) Empathy for their child}

Seven parents described feeling sad and hurt that their child had been cyberbullied and they had empathy for their child and their child's experiences, including a sense of loss of an ideal youth. One parent described how they had felt disappointed that the cyberbullying had tainted their child's experience of childhood and how [he/she] "wanted him to have happy teenage years making fun memories". Another parent was disappointed and saddened that [his/her] child had been mistreated by others: "It was heart-breaking to see a confident, lovely child who just desperately wanted to fit in with his peers be treated in this way". One parent described having empathy for [her/his] child because of the unfairness of the cyberbullying and the impact it had on her: "My child went from being so happy to feeling like she should be killed because [she] couldn't understand why people would target her in such an insidious way and feeling like she could do nothing and nothing would get done".

\section{c) Self-reflection}

Parents reflected on their own identities and skills, identifying instances of harm to their own emotional and mental well-being. Five parents reported reflecting on their identity and ability as parents when their child experienced cyberbullying; this often led to a feeling of failure. One parent explained: "It makes you feel as if you have failed your child". Another parent described how the cyberbullying had an impact on both of the parents' mental health: "We felt completely hopeless. It is a parent's role and instinct to protect their children. We felt we were powerless. To be honest I kind of had a breakdown which I tried very hard to hide from my daughter as I knew we had to be strong for her".

\section{d) Family stress}

Lastly, parents described feeling unable to undo the damage that cyberbullying had inflicted upon the whole family. Seven parents reported experiencing an increase in stress, stemming from the cyberbullying, which affected the wider family. One parent wondered "Why our family?", whilst another parent explained that the whole family was affected, and they were "subject to incorrect taunts [and] lies spread about us". Other parents found that the cyberbullying affected the relationship between parents. One parent explained that there was "some difference between mum and dad views on how to limit the risk and cell phone access" and this was a source of stress and tension. Another parent experienced a similar tension between parents about how the situation should be best managed: "Her father just wanted to beat the living daylights out of the students involved to teach them a lesson, which causes stress in the marriage as you are having to try and diffuse the situation". Parents also described that the incident had significantly affected family dynamics and damaged relationships: "The family dynamic has now been so thrown that one of our sons is alienated from his father as a result and now only lives with me".

\section{THEME 2: STAND UP, STEP IN, AND MAKE A STATEMENT}

Parents described a range of actions taken to access and provide support for their child. These fell into four categories: direct action, indirect action, monitoring the situation, and supporting their child. Six parents took more than one form of action, often simultaneously, such as approaching the bully's parent and the school around the same time. However, three parents described taking another approach when the first or subsequent approach did not stop the cyberbullying, for example, approaching the bully, and when that did not stop the 
cyberbullying, approaching the police. One parent described using multiple strategies of monitoring the situation to gather evidence, talking to the bullies' parents, and when those parents refused to intervene, they then approached the school and were referred to the police by the school. Some parents experienced adversity in the action-taking and support-seeking process, primarily due to other parents or the school declining to intervene: "I just had to stand up and step in and make a statement and stand by my son and my stance".

\section{a) Direct action (e.g. approaching the bully or their parents directly)}

Three parents described standing up and stepping in to take a direct form of action when they found out about the cyberbullying. These approaches included contacting the bully or the bully's parents directly i.e. "I contacted the bully myself and asked them questions around the bullying". These direct approaches had both positive and negative reactions from the bully and/or their parents. One parent explained: "The time I phoned other parents was successful", while another parent's experience was less successful:

I telephoned the parent of one of the main bullies and asked if he could get his daughter to remove comments as they were very damaging. He said he would get back to me and phoned the next morning to explain that he would not get his daughter to remove comments as she was entitled to express her opinion.

Furthermore, this parent then contacted a parent of another bully: "I phoned another parent who said 'It's not my fault no one likes your daughter and my daughter is not the only one". All three of these parents also used an indirect approach (see Category $2 b$, indirect action) in addition to the direct action.

\section{b) Indirect action (e.g. notifying, reporting, support/ advice-seeking)}

Eight parents described stepping in by taking some form of indirect action to address the cyberbullying: three of these parents also used direct approaches. Indirect approaches included notifying, reporting, and seeking advice. Parents reported contacting the school their child and the bully attended to make a complaint, to encourage them to take action, or to get support. Three parents also contacted the police. One parent stated: "I notified the police immediately". Another parent described contacting the police when the cyberbullying became an ongoing issue:
"When it didn't stop and would occur every now and then, I took it to the police". One parent described being referred on to the police by the school. These three parents' overall responses suggest they were satisfied with the police response to the situation.

Five parents explained that they had difficulty when they approached their child's school, with the school rejecting responsibility to intervene. Two parents described some initial hesitation from the school, but they stood by their stance and then experienced a change in the situation and an improved outcome for their child afterward. One parent said:

We gathered evidence and took it to the school, which is where the bullying began which then flowed into cyberbullying, with very explicit threats of violence. Initially, the principal tried to say it flowed the other way, but eventually took it seriously and the school environment has become safer as a result.

Another parent found that the school was unwilling or unable to take action: "We went to the school and the school said their hands were tied as the cyberbullying occurred outside of the school grounds. The school, however, advised us to go the police".

Overall, parents described mixed responses from their children's schools regarding the school's responsibility to intervene. One parent described how "the school put a support programme in place including a series of workshops to bolster the self-esteem of targets/victims to make them more bully-proof which is a really positive outcome". Other parents found that schools often failed to walk the talk: "The school tried to be supportive but in the end it was all talk". Some parents felt the school was more concerned about the bullies than the victims: "In my view the school wilfully supported and protected the perpetrators of the bullying". One parent described that "the school were a bit wary of getting involved", while another explained the ineffectiveness of their school's response and support for their child: "They tried to support him but it never really went away".

\section{c) Monitoring the situation}

Two parents described monitoring their child and the cyberbullying situation with a view of staying updated, gathering evidence to take to the school and police, and protecting their child from further cyberbullying. One parent described it as: 
At first I would check [the website/s] every day to see what they had written about her, secretly, as we tried to ban our daughter from accessing these sites. I became obsessed with it and my husband really tried to discourage me from reading it. Some of it I saved and printed and took to the police.

This particular situation also shows the use of indirect action and the occurrence of family stress illustrating the complex nature of cyberbullying intervention and multiple-strategy use by parents. Another parent explained that they "immediately changed phone number and she was only to give the number out to close friends".

\section{d) Supporting their child}

Four parents described stepping in to support their child while they experienced cyberbullying. Support mainly involved talking and accessing professional people who could help. Three parents took their child to counselling. One parent described talking with [his/her] child: "I talked to her about it and I also got her older sister to talk to her about it". Another parent described being supported by an in-school mediator; the "mediator spoke to both me and my daughter and made sure my daughter felt safe again at school without these girls being nasty to her. My daughter knew she could go to any of the teachers for support".

Four parents indicated they did not receive any form of support or advice while dealing with the cyberbullying. The first parent indicated that there was no support they would have liked as the incident was minor in scale. The second parent thought that support or advice would not help the situation and the only thing that would help was if the bullies were punished. The third parent wanted strategies to help their child deal with the cyberbullying directly. Lastly, the fourth parent wanted more intervention and victim-support from their school.

\section{THEME 3: THE MORE PEOPLE WHO STAND UP AND SAY SOMETHING ABOUT IT, THE BETTER IT WILL BE FOR EVERYONE}

Parents identified a number of people they thought were responsible for intervening in cyberbullying situations and who should support the victims of cyberbullying and their families. Parents identified that schools, parents of both the victims and the bully, and peers had a responsibility to intervene. Overall, parents recognised that many parties were responsible for intervening and some suggested that intervention needed to come from multiple areas in order to be effective. As one parent put it, "The more people who stand up and say something about it, the better it will be for everyone".

\section{a) School responsibility}

Three parents felt that the main responsibility for intervening in cyberbullying fell to schools if the cyberbullying occurred in school time. One of these three parents explained that they thought there should be "greater support and genuine support from schools if it is happening during school hours". Another reiterated that the best place to intervene is at "school if occurring in school time". Three other parents thought a more collaborative approach would help: "I think whoever sees cyberbullying going on any social media or through phones should do something about it". Another parent agreed: "If it comes from the school, then that is the place to address it, with the support and involvement of parents". One parent explained: "The school is 'in loco parentis' and is 100 percent responsible for bullying perpetrated by pupils against other pupils, whether the bullying takes the form of cyberbullying or another form".

\section{b) Parental responsibility}

Two parents reported that the parents of the bully were responsible and had a duty to stand up and say something about it to stop cyberbullying. One parent questioned the role of parents to guide their children's moral and ethical development: "Obviously the parents are accountable. Are they not teaching or raising their children with morals and ethics?" Another parent suggested that "a great part [of the responsibility] should be on the parents of the kids doing the cyberbullying".

Four parents suggested that the responsibility to intervene instead falls on the parents and families of the victim of cyberbullying. However, they recognised that "kids don't always want to tell their parents what is going on" but that "families need to be aware of it, that it is happening in their home".

\section{c) Peer responsibility}

Three parents said that there should be a greater peer/bystander responsibility to intervene in cyberbullying and to offer support to victims. One parent found that peers and friends were not always in a position to intervene: "Good friends would not stand up for her as they feared they would become a target". Another parent's child experienced re-victimisation after they intervened in the cyberbullying situation and this was an "embarrassment for [their] daughter as the 
whole school found out about it" and she was subsequently "further hassled as she had brought it out in the open". Another parent found that attempts to intervene could inflame the situation and make it worse: "Nothing seemed to stop these kids and it seemed to escalate with more kids jumping on the band wagon".

\section{DISCUSSION}

This study has analysed the experiences of ten parents whose children have been cyberbullied. Parents described their emotional responses, what actions they took, where they turned for support, and specified who they saw as responsible for intervening in cyberbullying situations. The findings of this study are similar to previous literature in that parents of bullying victims experienced a range of emotional responses. The current study and the existing literature, when juxtaposed, show some similarities between parents' responses to traditional forms of bullying and cyberbullying. Harcourt (2013) found that parents of bullied children experienced a range of emotional responses to their child's bullying - both negative (e.g. distress) and positive (e.g. increased resiliency) and this study also found negative (e.g. hopelessness) and positive (e.g. being proud of their child) emotional responses. Parents also described feeling sad and hurt, and that the cyberbullying had tainted their child's experience of the happy teenage years they had hoped for their child. Some parents reported feelings of failure in their parenting ability as they felt unable to protect their child. Furthermore, most parents reported stress in the wider family.

Harcourt (2013) found that the strategies parents take when their child experiences traditional bullying included supporting the child, seeking support, and approaching the school and the bully. The current study found that parents of children who are cyberbullied take similar action, that is, they also approached the school, the bully, and supported their child themselves. Parents in this study often took more than one form of action simultaneously, but sometimes this was when their first action failed to resolve the problem. Parents faced a variety of issues when trying to take action against cyberbullying. Most surprising were the responses given to one parent when she approached the parents of the cyberbullies. The parent of one of the cyberbullies explained that their daughter (the perpetrator) was entitled to express her opinion even though this was hurtful to the victim. This situation implies that some parents may believe that it is okay for their child to bully others, as this is their way of expressing their opinion. Future research could clarify parents' responses to their child cyberbullying others.
In the current study, parents identified a number of people they thought were responsible for intervening in cyberbullying situations and who should support the victims of cyberbullying and their families. Based on these responses, some parents agreed that everyone is responsible and others saw the school as responsible - but only if cyberbullying occurs on school grounds. Looking at traditional forms of bullying, Brown, Aalsma and Ott (2013) found that 10 out of 11 parents interviewed experienced ongoing opposition from their child's school to fully-address the bullying situation they were facing. Brown et al. (2013) further suggest that parents felt there was uncertainty over the school's role and which procedures they should follow when reporting and intervening in cases of bullying. The current study reiterates these findings for cyberbullying contexts and recognises that the lack of clarity around responsibility is impacting unified and effective intervention and support for children, young people, and their families.

\section{Limitations and directions for future research}

One main limitation of this study is the relatively small sample size $(n=10)$. One possible reason for this limitation is that parents may not be aware that their child is experiencing cyberbullying. Juvonen and Gross (2008) found that 90 percent of youth surveyed reported that they did not tell an adult about cyberbullying. Two main reasons that participants provided as to why they did not tell an adult were that they believed they needed to learn to deal with it themselves (50 percent) and they did not want their internet access limited (31 percent). Furthermore, Mishna, Saini and Solomon (2009) reiterate this finding that the main reason for nondisclosure of cyberbullying was a fear of loss of technology privileges. Mishna et al. (2009) go on to explain that other reasons for not telling an adult included a desire to be independent and a fear of exacerbating the cyberbullying.

As all parents specified that their child's cyberbullying occurred in New Zealand, future research could incorporate how people from different locations may experience cyberbullying situations. For example, the perspectives of parents from different cultures, religions, and locations could differ as school regulations, cultural customs, and government legislation vary. In addition, this could include diverse parenting dynamics such as single-parent, father-only, families. As the current study had only one participating father, and the remaining nine participants were the mother of the child they discussed, the father's perspective in responding to cyberbullying remains relatively under-researched. 
It is currently unclear if the experiences of fathers would differ regarding their emotional responses, action-taking, support-seeking, or views on responsibility of intervention.

Additionally, future research could examine what the ideal process for parents would be. That is, how they would like cyberbullying situations to be handled by schools and what type of prevention and intervention strategies their family would actually use. There remains confusion over the responsibility of schools to intervene in cyberbullying situations when they occur off school grounds. This confusion is not only from teacher's perspectives, as illustrated in Green et al. (2013) but this study suggests that parents are also divided in their views. Future research should endeavour to clarify these issues of responsibility to generate a consistent understanding for schools and families in addressing cyberbullying, both on and off school grounds.

\section{Enhancing the home-school partnership}

This study illustrates the varied and unclear response parents may receive when they approach their child's school about cyberbullying. To clarify these responses and enhance relationships in the future, a successful home-school partnership should be established. Home-school partnerships have been defined as being collaborative and mutually respectful, they respond to community needs, they are goal-oriented, and overall, they involve twoway communication between parents and schools (Bull, Brooking \& Campbell, 2008). Specifically, an enhanced home-school partnership enables parents and educators to deal with bullying from an ecological perspective (Jordan \& Austin, 2012). This collaborative partnership could enhance communication and collaboration for all forms of bullying, not only cyberbullying.

Some studies suggest that, not only are parents divided in the responsibility of schools to intervene in cyberbullying situations, but so too are teachers. Green et al. (2013) found that 92 percent of participating teachers and principals agreed that teachers should help students deal with cyberbullying within the school but only 61 percent agreed that the same should apply for cyberbullying outside of the school. This indicates disagreement among school personnel around the responsibility of dealing with cyberbullying. However, schools are required to abide by the National Administrative Guidelines (NAG). Specifically, NAG 5 requires that every school's Board of Trustees provides a safe physical and emotional environment for students.
Furthermore, anti-bullying policies are reviewed by the Education Review Office through Board Assurance Statements completed by a school's Board of Trustees before a review (Education Review Office, 2014), and during a school's review (Education Review Office, 2011). In addition, within the Board Assurance Statement, the Board of Trustees is asked if there is an internet safety policy in place for students and staff.

Most recently, the Bullying Prevention Advisory Group (BPAG) (2014) have released a new document to inform schools on prevention and response to bullying. Section 17.1 of this document states:

"To be effective, all aspects of bullying prevention and response should be integrated within the context of school safety and cyberbullying should not be dealt with in isolation from other forms of bullying. Boards of Trustees have responsibility for cybersafety under NAG 5 and establishing and maintaining a 'cybersafe' learning environment" (BPAG, 2014, p. 34).

In addition, Section 19.4 explains:

"There are no hard and fast rules about the extent of schools' responsibility for bullying that occurs off school premises. However, where bullying outside school is reported to school staff, it should be investigated and acted on. Schools that respond to bullying no matter where in their community the bullying occurs will respond to all bullying behaviour reported by students" (BPAG, 2014, p. 42).

This document also identifies that, in accordance with NAG 5, all schools should have a policy that defines bullying, indicates how it will be addressed, and that this policy will include cyberbullying. The inclusion of cyberbullying in this document, and particularly the recognition that bullying that occurs outside of school should be acted on, is a promising development for New Zealand. While this progression is encouraging, it is yet to be seen if there will be a significant impact on the prevention and intervention of cyberbullying experienced by young people and their families. Another recent development in New Zealand is the Harmful Digital Communications Bill (2014). This bill, currently waiting its second reading, would mean that posting a harmful digital communication intending to cause harm to someone, or to incite someone to commit suicide, would become punishable offences.

Another area of partnership for schools could be with the New Zealand Police. Three of the ten participating parents specified having approached the police about their child's cyberbullying experiences. These three parents' overall responses suggest they were satisfied with the police response to the situation 
and that the police had been able to act where the school could not, or would not; however, very little detail was provided. One way the school-police relationship has worked well is through Kia Kaha, a whole-school approach to bullying prevention developed by the New Zealand Police (Raskauskas, 2007). Further clarification may be needed in the police-school relationship about if, when, and how cyberbullying is referred to the police so that all families are consistently given the support they need to stop cyberbullying.

The current study further demonstrates the need for a cohesive and consistent stance against all forms of bullying. Such a position could be enhanced through further training to specifically address all forms of bullying. One such example of a consistent stance against all forms of bullying, using a whole-school programme with a nation-wide uptake, is the KiVa programme in Finland. Recent Finnish law reforms included an innovative and powerful amendment requiring education providers to plan and implement a programme against violence, bullying, and harassment (Salmivalli, Kärnä \& Poskiparta, 2011). Since this reform, the KiVa programme has been developed for schools providing comprehensive education to children that emphasises bystander behaviour, empathy, self-efficacy, and support to victims rather than bullies. Additionally, the KiVa programme includes guidelines for teachers to use if severe bullying cases do occur (Kärnä et al., 2013). The outcomes for KiVa schools include lower levels of self-reported bullying and victimisation, peer-reported victimisation, and positive effects on bystander behaviour (Kärnä et al., 2011). Additionally, some studies have also found significant reductions in cyberbullying for KiVa intervention schools (Salmivalli et al., 2011; Williford et al., 2013).

The current study shows that some victims of cyberbullying were re-victimised when their parent/s tried to take action or seek support, with multiple parents identifying that, as people found out, more bullying occurred. This illustrates the need for discretion and confidential support systems to be implemented where victims of cyber- and other types of bullying are able to seek help without the risk of being bullied further. This could also be improved through bystander support, such as in the KiVa programme which contains effective strategies that aim to utilise bystanders as 'defenders' (Salmivalli \& Poskiparta, 2012).

Parents in this study identified accessing support, intervention, and advice through their child's school, the bully and their family, and the police; however, there are a number of other sources of support that may be useful. One such source of information is the NetSafe (2009) website. NetSafe (2009) is a New Zealand-run website which provides information to parents, as well as young people and teachers, about bullying prevention, awareness, and support. For schools, NetSafe offers 'The NetSafe Kit' (NetSafe, n.d.) that schools may utilise to address student safety online, as well as to enhance overall digital citizenship. Included in this kit are templates to assist schools in developing digital citizenship policies, and staff and students responsible use agreements. Within a successful home-school partnership, as well as addressing cyberbullying, this could also be an appropriate channel to develop digital literacy for the whole family, whereby schools and families develop mutual expectations of use, safety and consequences for improper use of technology.

Another implication for parents is that it is important to recognise that victims of cyberbullying may not report that they are being bullied. One reason for this, as identified by Juvonen and Gross (2008) and Mishna et al. (2009), is because young people do not want their access to technology removed. As such, an open dialogue about online safety and an emphasis on tackling the issue, not punishing the victim, may enhance cyberbullying disclosure to adults. Furthermore, it is also important to recognise that being a cybervictim is not mutually-exclusive from being a cyberbully. Wang, lannotti and Nansel (2009) surveyed 7,182 young people in Grades 6-10 and found that 13.6 percent were involved in cyberbullying. Interestingly, of this 13.6 percent who were involved, 27.4 percent were bullies, 40 percent were victims, and 32.6 percent were both bullies and victims of cyberbullying. Overall, parents of all young people could benefit from an open dialogue about online safety, bullying and promoting 'cyber kindness' (Cassidy et al., 2012).

\section{CONCLUSION}

This study has examined parents' experiences of supporting their child through cyberbullying. This study contributes to a developing body of literature that analyses the experiences of many perspectives in both bullying and cyberbullying. Participants reported experiencing a wide range of emotional responses and using a wide range of strategies in response to their child being cyberbullied. Responses were varied over who had the responsibility to intervene in cyberbullying. The findings from this study intend to reflect on the experiences and perspectives of parents as a way to enhance a collaborative and ecological approach to cyberbullying prevention and intervention. 


\section{REFERENCES}

Beale, A., \& Hall, K. (2007). Cyberbullying: What school administrators (and parents) can do. The Clearing House, 81, 8-12.

Braun, V., \& Clarke, V. (2006). Using thematic analysis in psychology. Qualitative Research in Psychology, 3(2), 77-101.

Brown, J. R., Aalsma, M. C., \& Ott, M. A. (2013). The experiences of parents who report youth bullying victimisation to school officials. Journal of Interpersonal Violence, 28, 494-518.

Bull, A., Brooking, K., \& Campbell, R. (2008). Successful home-school partnerships. (A report prepared for the Ministry of Education). Wellington: New Zealand Council for Educational Research.

Bullying Prevention Advisory Group (2014). Bullying prevention and response: A guide for schools. Retrieved from http://www.education.govt.nz/ assets/Documents/School/Bullying-prevention/ Bullying-prevention-and-response-A-guide-forschools.pdf

Cassidy, W., Brown, K., \& Jackson, M. (2012). "Making kind cool": Parents' suggestions for preventing cyber bullying and fostering cyber kindness. Journal of Educational Computing Research, 46, 415-436.

Dehue, F., Bolman, C., \& Völlink, T. (2008). Cyberbullying: Youngsters' experiences and parental perception. Cyberpsychology \& Behavior, 11, 217-223.

Education Review Office (2014). Pre-review information schools 2015. Retrieved from http:// ero.govt.nz/Review-Process/For-Schools-andKura-Kaupapa-Maori/Review-Documentation-forSchools\#ast

Education Review Office (2011). Evaluation indicators for school reviews 2011. Retrieved from http:// ero.govt.nz/Review-Process/Frameworks-andEvaluation-Indicators-for-ERO-Reviews

Green, V. A., Harcourt, S., Mattioni, L., \& Prior, T. (2013). Bullying in New Zealand schools: A final report. Wellington, New Zealand: Victoria University of Wellington. Retrieved from http:// www.victoria.ac.nz/education/pdf/Bullying-in-NZSchools.pdf

Harcourt, S. (2013). It is everyone's problem: Parents' experiences of bullying. (Unpublished Master of Educational Psychology Report). Victoria University of Wellington, New Zealand.
Harcourt, S., Jasperse, M., \& Green, V. A. (2014). "We were sad and we were angry": A systematic review of parents' perspectives on bullying. Child \& Youth Care Forum, 43, 373-391.

Harmful Digital Communications Bill (2014). [As Reported from the Justice and Electoral Committee on 27 May 2014]. Retrieved from http://www. legislation.govt.nz/bill/government/2013/0168/ latest/DLM5711810.html?search=ts_act\%4 Obill\%40regulation\%40deemedreg_digital_ resel_25_a\&p=1

Hinduja, S., \& Patchin, J. W. (2007). Cyberbullying: An exploratory analysis of factors related to offending and victimization. Deviant Behavior, 29, 129-156.

Jordan, K., \& Austin, J. (2012). A review of the literature on bullying in US schools and how a parent-educator partnership can be an effective way to handle bullying. Journal of Aggression, Maltreatment \& Trauma, 21, 440-458.

Juvonen, J., \& Gross, E. F. (2008). Extending the school grounds? - Bullying experiences in cyberspace. The Journal of School Health, 78, 496-505.

Kärnä, A., Voeten, M., Little, T. D., Alanen, E., Poskiparta, E., \& Salmivalli, C. (2013). Effectiveness of the KiVa antibullying program: Grades 1-3 and 7-9. Journal of Educational Psychology, 105, 535-551.

Kärnä, A., Voeten, M., Little, T. D., Poskiparta, E., Kaljonen, A., \& Salmivalli, C. (2011). A largescale evaluation of the KiVa antibullying program: Grades 4-6. Child Development, 82, 311-330.

Mark, L. K. (2009). Student, educator and parent perceptions of cyberbullying in three Hawai'i middle schools. Doctoral dissertation. Retrieved from ProQuest Dissertations and Theses (UMI No. 1468496).

Mishna, F., Saini, M., \& Solomon, S. (2009). Ongoing and online: Children and youth's perceptions of cyber bullying. Children and Youth Services Review, 31, 1222-1228.

NetSafe (2009). Cyberbullying: Information and advice for parents. Retrieved from http://www. cyberbullying.org.nz/parents/

NetSafe (n.d.). The NetSafe kit for schools. Retrieved from http://www.netsafe.org.nz/the-netsafe-kit-forschools/ 
O'Connor, A., Jackson, L., Goldsmith, L., \& Skirton, H. (2014). Can I get a retweet please? Health research recruitment and the Twittersphere. Journal of Advanced Nursing, 70, 599-609.

Olweus, D. (1993). Bullying at school: What we know and what we can do. Oxford, UK: Blackwell.

Raskauskas, J. (2007). Evaluation of the Kia Kaha Anti Bullying Programme for Students in Years 5-8, Wellington: New Zealand Police.

Salmivalli, C., Kärnä, A., \& Poskiparta, E. (2011). Counteracting bullying in Finland: The KiVa program and its effects on different forms of being bullied. International Journal of Behavioral Development, 35, 405-411.

Salmivalli, C., \& Poskiparta, E. (2012). Making bullying prevention a priority in Finnish schools: The KiVa antibullying program. New Directions for Youth Development, 133, 41-53.

Sawyer, J-L., Mishna, F., Pepler, D., \& Wiener, J. (2011). The missing voice: Parents' perspectives of bullying. Children and Youth Services Review, 33, 1795-1803.

Smith, P. K., \& Slonje, R. (2010). Cyberbullying: The nature and extent of a new kind of bullying in and out of school. In S. R. Jimerson, S. M. Swearer \& D. L. Espelage (Eds.), Handbook of bullying in schools: An international perspective (pp. 249-262). New York, NY: Routledge.

Turner, M. G., Exum, M. L., Brame, R., \& Holt, T. J. (2013). Bullying victimization and adolescent mental health: General and typological effects across sex. Journal of Criminal Justice, 41, 53-59.
Wang, J., lannotti, R. J., \& Nansel, T. R. (2009). School bullying among adolescents in the United States: Physical, verbal, relational, and cyber. Journal of Adolescent Health, 45, 368-375.

Williford, A., Elledge, L. C., Boulton, A. J., DePaolis, K. J., Little, T. D., \& Salmivalli, C. (2013). Effects of the KiVa antibullying program on cyberbullying and cybervictimization frequency among Finnish youth. Journal of Clinical Child \& Adolescent Psychology, 42(6), 820-833.

Ybarra, M. L., \& Mitchell, K. J. (2004). Youth engaging in online harassment: Associations with caregiverchild relationships, Internet use, and personal characteristics. Journal of Adolescence, 27, 319336.

\section{ACKNOWLEDGEMENTS}

We would like to sincerely thank the participants for their willingness to take part in the study. The completion of this project was supported in part by a Sarah Anne Rhodes Scholarship and Ministry of Education Educational Psychology Masters Scholarship, both awarded to the first author. 


\section{AUTHOR PROFILES}

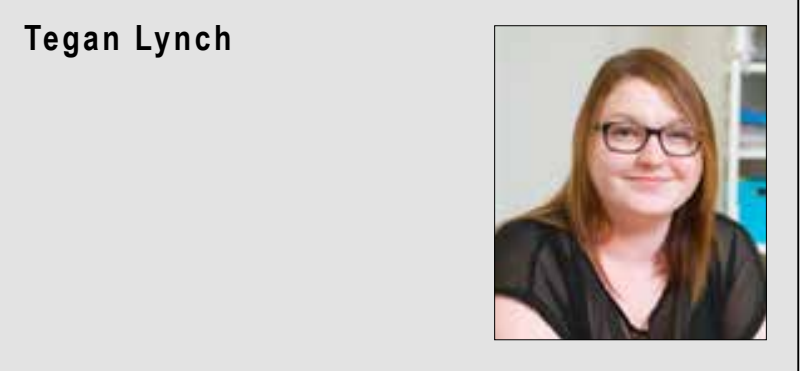

Tegan Lynch is a current PhD student in the School of Education at Victoria University of Wellington, working under the supervision of Professor Vanessa Green and Dr Paul Jose. Her research interests include bullying, particularly relational and cyberbullying, and the impact this can have on families.

\section{Email:}

Tegan.Lynch@vuw.ac.nz

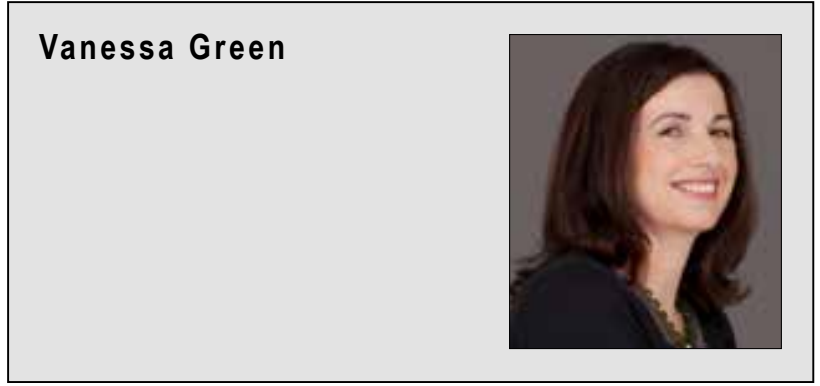

Vanessa A. Green, PhD., is a professor in the School of Education at Victoria University of Wellington. As a developmental psychologist her work within the field of education focuses primarily on the social, emotional and communicative development of children with and without developmental disabilities. She is currently conducting research on the intergenerational nature of bullying and victimisation. She serves on the editorial board of Focus on Autism and Developmental Disabilities and is Associate Editor for Intervention in School and Clinic and International Journal of Disability, Development and Education.

\section{Email:}

Vanessa.Green@vuw.ac.nz

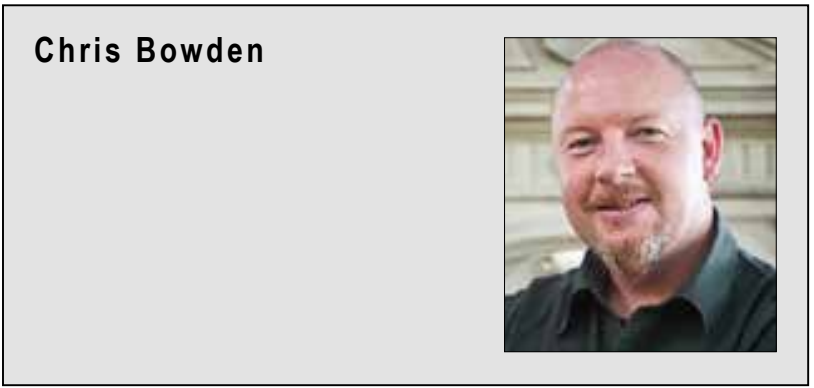

Chris Bowden is a lecturer in the School of Education at Victoria University of Wellington. He teaches in the areas of human development, adolescent development and youth issues. His research interests include risk and resiliency, mental health, suicide bereavement and educational interventions.

\section{Email:}

Chris.Bowden@vuw.ac.nz

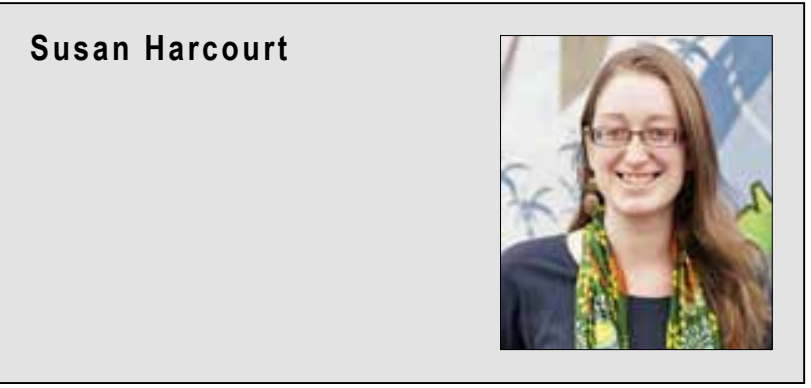

Susan Harcourt completed her Master of Educational Psychology at Victoria University of Wellington in 2013. Her research interests include social and emotional development, autism spectrum disorders, and the effects of bullying on students, teachers, families, and communities. Susan is currently living in New York City, pursuing further work experience in the field of special needs education.

\section{Email:}

susan.harcourt@hotmail.com 